\title{
Glutamate receptor antagonist infusions into the basolateral and medial amygdala reveal differential contributions to olfactory vs. context fear conditioning and expression
}

\author{
David L. Walker, ${ }^{1}$ Gayla Y. Paschall, and Michael Davis \\ Emory University School of Medicine, Department of Psychiatry and Behavioral Sciences, Atlanta, Georgia 30329, USA
}

\begin{abstract}
The basolateral amygdala's involvement in fear acquisition and expression to visual and auditory stimuli is well known. The involvement of the basolateral and other amygdala areas in fear acquisition and expression to stimuli of other modalities is less certain. We evaluated the contribution of the basolateral and medial amygdala to olfactory and to context fear and fear conditioning by infusing into these areas the NMDA receptor antagonist AP5, the AMPA/kainate receptor antagonist NBQX, or vehicle prior to either odor-shock pairings or fear-potentiated startle testing. Pre-training AP5 infusions into the basolateral amygdala disrupted fear conditioning to the odor but not the context conditioned stimulus (CS). Pre-test NBQX infusions disrupted fear-potentiated startle to the odor but not context CS. Neither compound blocked fear conditioning when infused into the medial amygdala prior to training, but pre-test NBQX infusions did block fear-potentiated startle. The results confirm and extend recent findings suggesting a role for the basolateral amygdala in olfactory fear and fear conditioning, reveal an unexpected dissociation of the basolateral amygdala's involvement in discrete cue versus context fear and fear conditioning, and implicate for the first time the medial amygdala in fear-potentiated startle.
\end{abstract}

For auditory and visual stimuli, the amygdala plays a key role in fear conditioning and fear expression as assessed with several behavioral measures (cf., Fendt and Fanselow 1999; Davis 2000; LeDoux 2000). We have found, for example, that pre-test infusions into the basolateral amygdala (i.e., the lateral, basolateral, and basomedial nuclei) of $\alpha$-amino-3-hydroxy-5-methylisoxazole-4-propionic acid (AMPA)/kainate receptor antagonists block fear-potentiated startle to visual and auditory conditioned fear stimuli (CSs), and that pre-training (i.e., light-shock or toneshock) infusions of either $N$-methyl-D-aspartate (NMDA) receptor antagonists or AMPA/kainate receptor antagonists block fear conditioning (cf., Walker and Davis 2002b). In most (e.g., Miserendino et al. 1990; Campeau et al. 1992; Gewirtz and Davis 1997), but not all (e.g., Fendt 2001; see also Lee et al. 2001) cases, pre-test intra-amygdala infusions of NMDA receptor antagonists have not been found to disrupt fear expression to auditory and visual CSs. Similar results have been obtained from other laboratories using different treatments and other fear-related behaviors (e.g., LeDoux et al. 1990; Muller et al. 1997; Groenink et al. 2000; Rodrigues et al. 2001).

Visual and auditory information reach the basolateral amygdala indirectly via intermediary structures such as auditory and visual thalamus and perirhinal cortex. Olfactory information also reaches the basolateral amygdala indirectly. Uniquely, however, the main and accessory olfactory bulbs also send direct projections to several amygdala areas including the medial and cortical nuclei, the nucleus of the lateral olfactory tract, and the periamygdaloid cortex (cf., Alheid et al. 1995; McDonald 1998; Pitkanen 2000). For olfactory fear and fear conditioning, the relative contribution of direct versus indirect inputs is unknown.

\footnotetext{
'Corresponding author.

E-mail dlwalke@emory.edu; fax (404) 727-8070

Article published online ahead of print. Article and publication date are at http://www.learnmem.org/cgi/doi/10.1101/lm.87105.
}

Using freezing as a behavioral measure of fear, Otto and colleagues have begun to assess the contribution of several brain areas. Lesion results suggest that the basolateral amygdala mediates fear responses to olfactory CSs (Cousens and Otto 1998) perhaps via afferents from the perirhinal cortex (Herzog and Otto 1997). Accompanying Fos data support this view and suggest also that the medial nucleus of the amygdala nucleus may participate in olfactory fear conditioning (Schettino and Otto 2001).

For the present study, there were three primary goals. First, we wished to confirm with an alternative behavioral measure (i.e., with fear-potentiated startle) the involvement of the basolateral amygdala in fear expression to an olfactory CS. Second, we wished to determine if the basolateral amygdala also participates in olfactory fear learning. And third, we wished to evaluate the contribution of the medial amygdala nucleus to both. The general strategy was to infuse glutamate receptor antagonists (either AMPA/kainate or NMDA receptor antagonists) into the area of interest either immediately prior to fear conditioning or immediately prior to testing. A disruption of fear-potentiated startle, assessed $48 \mathrm{~h}$ after training, would suggest an involvement of these areas either in olfactory fear learning (i.e., with pre-training infusions) or in fear expression (i.e., with pre-test infusions). The experimental design also allowed us to measure fear-potentiated startle to the context, and to evaluate the impact of these treatments on context fear and fear conditioning.

\section{Results}

Experiments $1 \mathrm{~A}$ and $\mathrm{B}$ : Effect on fear conditioning and fear-potentiated startle of NMDA receptor blockade in the basolateral amygdala

\section{Experiment IA (Acquisition)}

Fifteen rats were infused with either artificial cerebrospinal fluid (ACSF; $N=8$ ) or DL-2-amino-5-phosphonopentanoic acid (DL- 
AP5; $2.5 \mu \mathrm{g} /$ side; $N=7$ ). This dose was selected based on previous results from Campeau et al. (1992) and Miserendino et al. (1990). Fifteen minutes after the infusions were completed, rats were placed into the test chamber and $5 \mathrm{~min}$ later received the first of five odor-shock pairings (ITI $=4 \mathrm{~min}$ ). Three ACSF-infused rats were later found not to have bilateral basolateral amygdala cannulations (as determined based on inclusion criteria described in the Methods section). The data from these rats were excluded from the statistical analyses (paired $t$-tests) that follow. Placements for the remaining animals are shown in Figure 1 as filled circles. As shown in Figure 2 (leftmost bars), fear-potentiated startle was significantly lower in rats that were trained following AP5 infusions into the basolateral amygdala compared to rats that were trained following ACSF infusions, $t(11)=2.92$. Mean footshock reactivity $( \pm$ S.E.M.), measured using the same procedure used to measure startle amplitude during training, was similar in the ACSF $(1188 \pm 295)$ and AP5 (1048 \pm 301) groups.

Because the primary goal of Experiment $1 \mathrm{~A}$ was to demonstrate an involvement of the basolateral amygdala in olfactory fear conditioning, and because this was accomplished using AP5, we did not also evaluate the involvement of the basolateral amygdala in olfactory fear conditioning with the other compound used in this study, 1,2,3,4-tetrahydro-6-nitro-2,3-dioxobenzo[f]quinoxa-line-7-sulfonamide (NBQX).

\section{Experiment $1 B$ (Expression)}

Using a counterbalanced design with test days separated by $48 \mathrm{~h}$, 10 rats received pre-test infusions of ACSF and, on another day, D,L-AP5 $(2.5 \mu \mathrm{g} /$ side $)$. Immediately after the infusion procedure

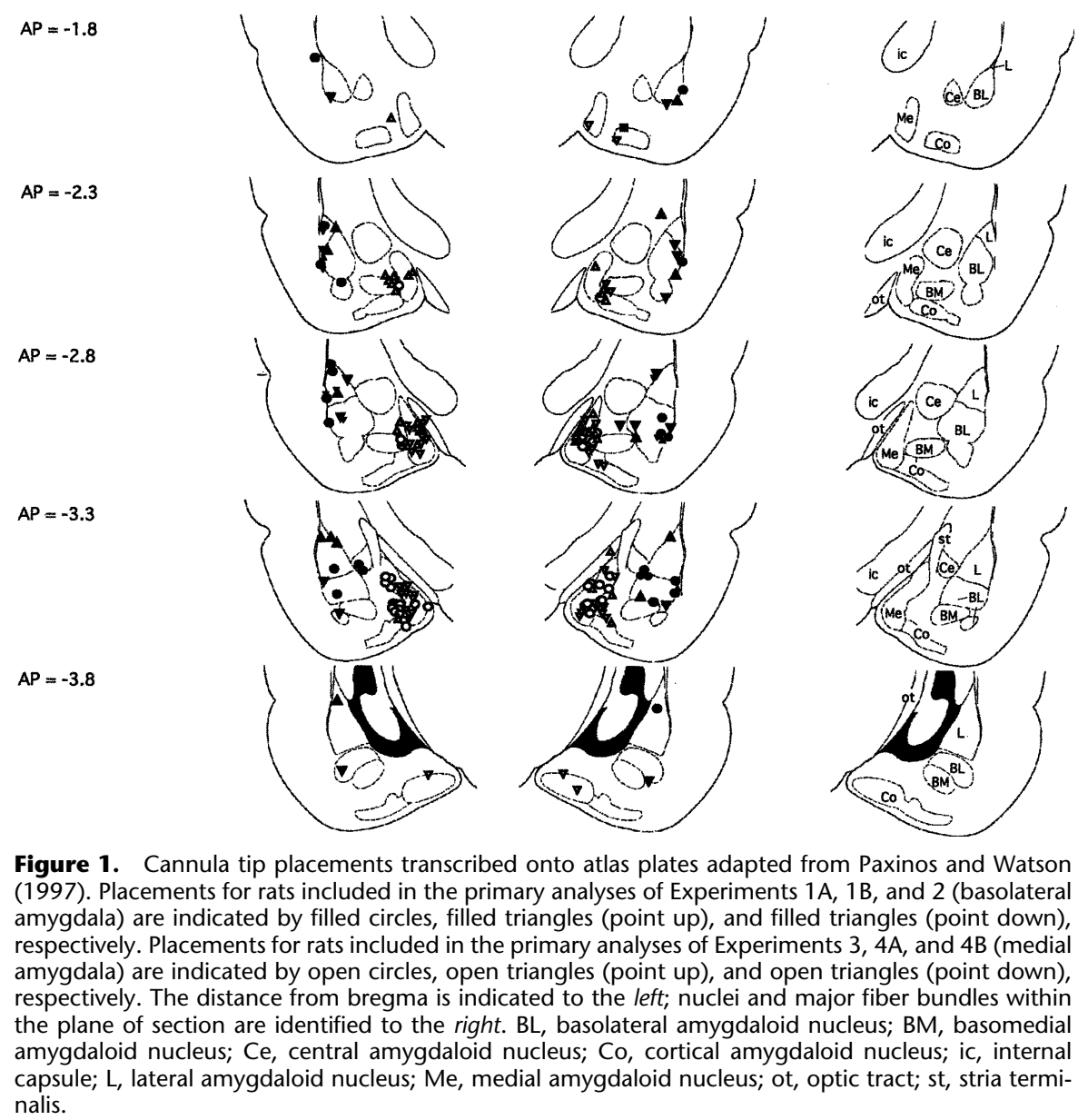

was completed, rats were placed into the test chamber. Collection of test data for odor-potentiated startle began 20 min later. Data from two rats that did not have bilateral cannulations in the basolateral amygdala were excluded from the statistical analysis that follows. Placements for the remaining animals are indicated in Figure 1 by filled triangles (point up). As shown in Figure 2 (middle bars), AP5 did not significantly influence fear-potentiated startle, $t(7)=0.44$, when infused into the basolateral amygdala prior to testing.

Although extinction from the first to the second test is a potential concern in counterbalanced designs of this sort, there was no evidence of extinction in this experiment, probably due to the small number (i.e., 10) of test/extinction trials. Mean percent change scores for rats that received ACSF on day 1 followed by AP5 on day $2(N=3)$ were $25.1 \pm 4.9$ and $56.4 \pm 27.7$, respectively. For rats that received AP5 on day 1 followed by ACSF on day $2(N=5)$, mean percent change scores were $88.7 \pm 26.2$ and $91.0 \pm 50.2$, respectively.

\section{Experiment 2: Effect on fear-potentiated startle of AMPA/kainate receptor blockade in the basolateral amygdala}

Using a counterbalanced design with test days separated by $48 \mathrm{~h}$, 14 rats were infused with ACSF and NBQX (3 $\mu \mathrm{g} /$ side- - selected on the basis of previous findings from Walker and Davis 1997) disodium salt prior to fear-potentiated startle testing. Data from two rats that did not have bilateral cannulations in the basolateral amygdala were excluded from the statistical analyses that follow. Placements for the 12 remaining animals are indicated in Figure 1 by filled triangles (point down). As shown in Figure 2 (rightmost bars), NBQX significantly disrupted fear-potentiated startle, $t(11)=4.65$.

As with Experiment 1, there was little evidence of between-session extinction. The mean percent change score for rats that received ACSF on day 1 $(N=7)$ was $127.6 \pm 39.3$, and for rats that received ACSF on day $2(N=5)$, $89.6 \pm 34.4$. The difference was not significant $(P=0.41)$.

\section{Experiment 3: Effect on olfactory fear conditioning of AMPA/ kainate and NMDA receptor blockade in the medial nucleus of the amygdala}

Thirty rats were infused with ACSF, NBQX (3 $\mu \mathrm{g} /$ side) disodium salt, or D,LAP5 $(2.5 \mu \mathrm{g} /$ side $)$ prior to odor-shock pairings. Data from 10 rats that did not have bilateral cannulations in or immediately adjacent to the medial amygdala nucleus were excluded from the statistical analysis (single factor ANOVA) that follows. Placements for the remaining animals (ACSF $[N=7]$, AP5 $[N=8]$, $\operatorname{NBQX}[N=6])$ are indicated in Figure 1 by open circles. As shown in Figure 3 (leftmost bars), the antagonists did not disrupt fear-conditioning to the olfactory CS. In fact, mean percent potentiation scores were higher in these groups 


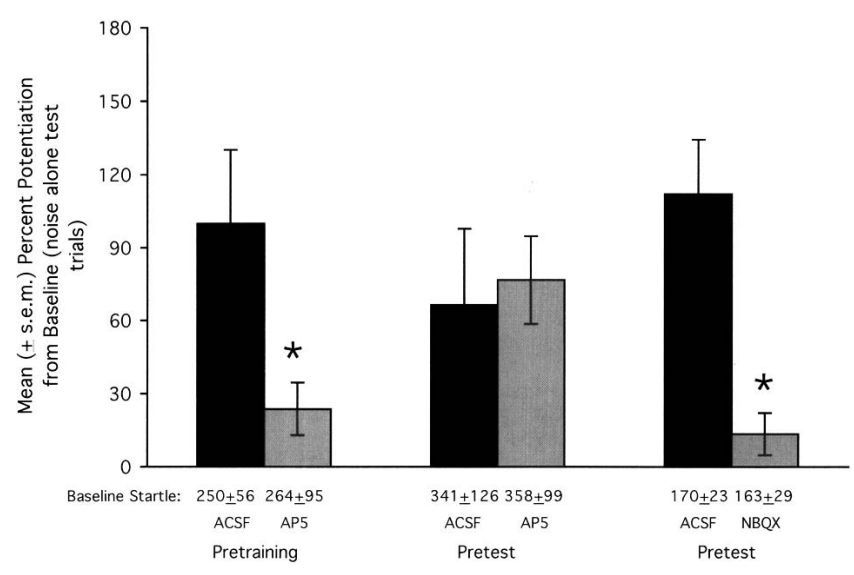

Figure 2. Effect on fear conditioning and fear-potentiated startle of glutamate receptor antagonist infusions into the basolateral amygdala. The NMDA receptor antagonist AP5 disrupted fear conditioning to an olfactory CS when infused prior to training (leftmost bars) but did not disrupt fear-potentiated startle when infused prior to testing (middle bars). The AMPA/kainate receptor antagonist NBQX did disrupt fearpotentiated startle when infused prior to testing (rightmost bars). Baseline startle amplitude (i.e., from noise-alone test trials), from which percent potentiation scores are derived, is indicated immediately below each bar. ${ }^{\star} P<0.05$ vs. ACSF control infusions.

compared to the ACSF group, although the difference was not statistically significant, $F_{(2,18)}=2.48(P=0.12)$. We believe that the higher mean levels of fear-potentiated startle in rats infused with AP5 or NBQX prior to training is at least partly an artifact of the atypically low level of fear-potentiated startle in the ACSF group. Across all experiments in this study, the average level of odor-potentiated startle in rats either trained or tested with ACSF was $92.4 \pm 12$. This is just slightly less than that observed for rats infused with AP5 prior to training and moderately less than rats infused with NBQX prior to training.

\section{Experiments 4A and 4B: Effect on fear-potentiated startle of AMPA/kainate receptor antagonist infusions into the medial nucleus of the amygdala}

\section{Olfactory CS (Experiment 4A)}

Twenty-nine rats were infused with ACSF or NBQX ( $3 \mu \mathrm{g} / \mathrm{side})$ disodium salt prior to fear-potentiated startle testing. Data from 12 rats that did not have bilateral cannulations in or immediately adjacent to the medial amygdala nucleus were excluded from the statistical analysis (independent sample $t$-test) that follows. Placements for the remaining animals (ACSF $[N=7]$, NBQX $[N=10]$ ) are indicated in Figure 1 by open triangles (point up). As shown in Figure 3 (middle bars), NBQX significantly disrupted fear-potentiated startle to the olfactory CS, $t(15)=2.41$.

\section{Visual CS (Experiment 4B)}

Because the medial nucleus of the amygdala receives a prominent olfactory input relative to other modalities (cf., DeOlmos et al. 1985; Pitkanen 2000), we wondered if the disruptive effect of NBQX was modality-specific. To this end, an additional group of rats $(N=31)$ was trained as previously described, this time using a visual rather than olfactory stimulus. Data from 10 rats that did not have bilateral cannulations in or immediately adjacent to the medial amygdala nucleus are excluded from the statistical analysis that follows. Placements for the remaining animals (ACSF $[N=8]$, NBQX $[N=13])$ are indicated in Figure 1 by open triangles (point down). As shown in Figure 3 (rightmost bars),
NBQX significantly disrupted fear-potentiated startle to the visual CS, $t(19)=2.26$.

Because we were able to demonstrate an involvement of the medial amygdala in fear-potentiated startle using NBQX and because there was not an AP5-induced disruption of fear conditioning with pre-training infusions, we did not also assess the involvement of the medial amygdala in fear-potentiated startle with AP5.

\section{Treatment effects on "baseline" startle amplitude}

As also indicated in Figure 3, baseline startle amplitude (i.e., on noise-alone trials) was markedly lower in rats that received pretest NBQX infusions into the medial nucleus of the amygdala compared to rats that received ACSF infusions. In fact, an ANOVA on baseline startle amplitude using rats from Experiments $4 \mathrm{~A}$ together with those of $4 \mathrm{~B}$ indicated a significant effect of drug treatment (ACSF vs. NBQX), $F_{(1,34)}=16.02$, but not modality (rats from Experiment $4 \mathrm{~A}$ vs. $4 \mathrm{~B}$ ).

Because rats were trained and tested in the same chamber, we considered the possibility that startle amplitude was elevated in ACSF-infused rats due to context conditioning and that this effect was blocked by NBQX. For the purest assessment of context conditioning (i.e., one not contaminated by intermixed CS test trials), we compared startle amplitude on the 30 noise-alone test trials that occurred at the beginning of the pre-shock acclimation session with startle amplitude on the 30 noise-alone test trials that occurred at the beginning of the post-conditioning test session (i.e., the noise-alone test trials that preceded the first CS presentation; see Methods section for details). Indeed, the startle amplitude of ACSF- but not NBQX-infused rats increased markedly from the pre-conditioning acclimation session to the postconditioning test session (see Fig. 4, leftmost bars). Statistically, an ANOVA on the between-session percent change scores indicated a significant Treatment effect, $F_{(1,34)}=4.93$, but not a significant Modality or interaction effect. The absolute level of startle prior to conditioning was somewhat, although not significantly, lower in the groups that later received NBQX (i.e., vs. the groups that later received ACSF). We do not believe that this in any way accounts for the apparent disruption of context conditioning insofar as we have previously found that percent poten-

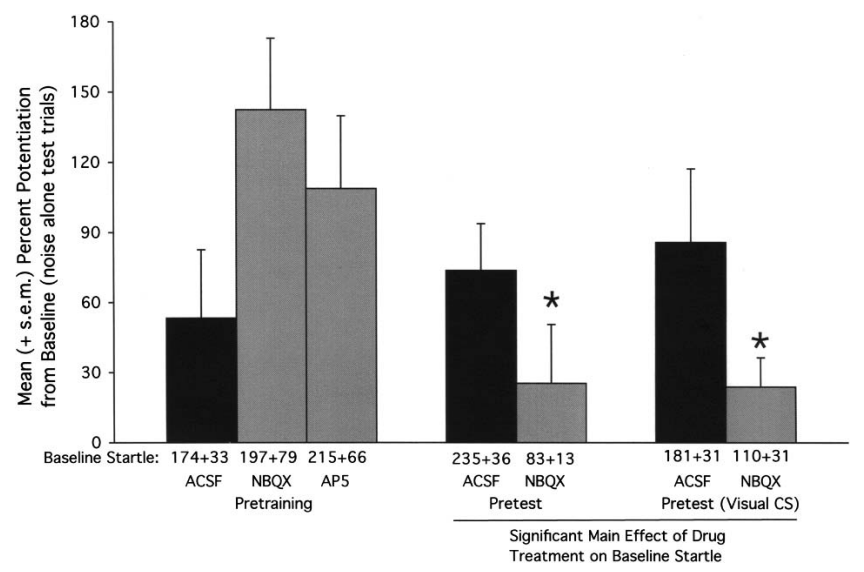

Figure 3. Effect on fear conditioning and fear-potentiated startle of glutamate receptor antagonist infusions into the medial nucleus of the amygdala. Neither AP5 nor NBQX disrupted fear conditioning to an olfactory CS when infused prior to training (leftmost bars). When infused prior to testing, NBQX disrupted fear-potentiated startle to an olfactory CS (middle bars) and to a visual CS (rightmost bars), and significantly reduced startle amplitude on noise-alone trials (indicated immediately below each bar). ${ }^{*} P<0.05$ vs. ACSF control infusions.

\section{Learning \& Memory \\ www.learnmem.org}




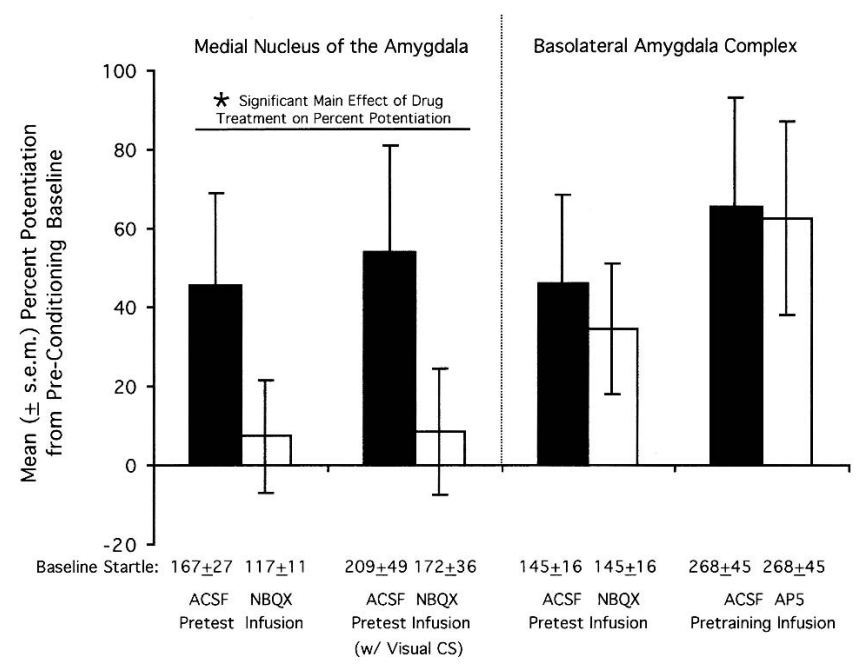

Figure 4. Effect of glutamate receptor antagonist infusions into the basolateral and medial nucleus of the amygdala on pre- to postconditioning changes in baseline startle amplitude. Pre-test infusions of NBQX into the medial nucleus of the amygdala disrupted pre- to postconditioning increases of startle amplitude on noise-alone trials (leftmost bars). In contrast, pre-test NBQX infusions into the basolateral amygdala did not disrupt these increases, nor did pre-training infusions of AP5 (rightmost bars). Baseline startle amplitude from the final preconditioning acclimation session, from which percent potentiation scores are derived, is indicated immediately below each bar.

tiation scores (as opposed to absolute difference scores) are independent of baseline startle amplitude (Walker and Davis 2002a).

For comparison, we also evaluated the effect of pre-test NBQX and pre-training AP5 infusions into the basolateral amygdala (treatments shown in Experiments $1 \mathrm{~A}$ and 2 to disrupt fear conditioning and fear-potentiated startle to the discrete olfactory CS) on pre- to post-conditioning changes in baseline startle amplitude. Surprisingly, although these treatments potently disrupted olfactory fear conditioning and fear-potentiated startle, they had no obvious effect on the pre- to post-conditioning increases (see Fig. 4, right bars).

To ensure that these increases do in fact reflect context conditioning as opposed, for example, to a nonspecific shockinduced sensitization of startle amplitude, other rats were tested as before, but received training in a distinctively different chamber (see Methods section for details). Although these rats received the same number, intensity, and schedule of shocks as in our other experiments, they did not show the same pre-training to post-training increase. In fact, mean startle amplitude remained remarkably stable (i.e., $239.0 \pm 37.6$ prior to conditioning and $235.4 \pm 46.7$ after conditioning).

NBQX infused into the medial nucleus of the amygdala might have specifically disrupted the influence of context on startle, but might alternatively have depressed startle nonselectively and simply masked the influence of context. To discriminate between these alternatives, we evaluated the effect of NBQX infusions in untrained animals. Nine rats were implanted with cannula aimed at the medial nucleus of the amygdala. One week later, these rats were placed into the startle chamber whereupon they received, after a $5 \mathrm{~min}$ acclimation period, 30 95-dB noise bursts and 30 intermixed 110-dB noise bursts. Rats received infusions of either ACSF or $3 \mu \mathrm{g} /$ side NBQX (the order of treatments was counterbalanced) 24 and $72 \mathrm{~h}$ later and were retested using the same protocol. The $110-\mathrm{dB}$ noise bursts were included to ensure that a negative finding could not be attributed to baseline-dependent NBQX effects (e.g., an effect that was only apparent at higher startle amplitudes such as those that would have occurred to 95-dB stimuli in conditioned rats). Five rats were found to have misplaced cannula. Results from the remaining animals are shown in Figure 5. NBQX infusions did not decrease startle amplitude to either 95- or 110-dB noise bursts. Thus, the lower startle levels in NBQX- compared with ACSF-infused rats from Experiments $4 \mathrm{~A}$ and $4 \mathrm{~B}$ do not appear to reflect a general decrease of startle amplitude but reflect, instead, a specific disruption of the pre- to post-conditioning increase.

\section{Influence of cannula placement on the magnitude of the NBQX effect}

Because the medial amygdala lies just medial to the basomedial and cortical amygdala nuclei, and because drugs infused into the medial nucleus might diffuse dorsally along the cannula track where they might also influence the central nucleus of the amygdala (where NBQX infusions have previously been shown to disrupt fear-potentiated startle to a visual CS (Walker and Davis 1997), we considered the possibility that the effects of pre-test infusions into the medial nucleus might be mediated by actions elsewhere.

For fear-potentiated startle to the olfactory stimulus (Experiment $4 \mathrm{~A}$ ), there were $10 \mathrm{NBQX}$-infused rats with bilateral placements in or sufficiently near the medial nucleus of the amygdala to be scored as hits, and four rats with only a single cannula in the medial amygdala and a second cannula elsewhere. As shown in Figure 6 (left), fear-potentiated startle to the olfactory CS in rats with bilateral hits was significantly lower, $t(12)=3.21$, than in rats that did not have bilaterally accurate placements. Thus, the effect of NBQX on fear-potentiated startle to an olfactory CS was anatomically specific and appeared to require bilateral inactivation of the medial nucleus of the amygdala per se.

We also looked for placement-effect correlations using data from all of the NBQX-infused rats in Experiment 4A. For these analyses, the distance of one cannula tip to either the medial, basomedial, cortical, or central amygdala nuclei was added to the distance of the other cannula to the same structure on the opposite side of the brain, and this summed distance was entered into a correlation analysis (i.e., one Pearson Product-Moment Correlation for each of four structures) using percent potentiation as the correlated variable. Percent potentiation scores were significantly correlated $(r=0.82)$ with cannula tip distance to the medial nucleus of the amygdala (see Fig. 6, right), but were not significantly correlated with cannula tip distance from the other three structures $\left(r^{\prime} \mathrm{s}=0.15,-0.29\right.$, and -0.45 for the central, cortical, and basomedial nuclei, respectively).

For fear-potentiated startle to the visual stimulus (Experiment $4 \mathrm{~B}$ ), percent potentiation scores were not significantly correlated with proximity to any of the four structures considered (there were too few animals with missed placements to mean-

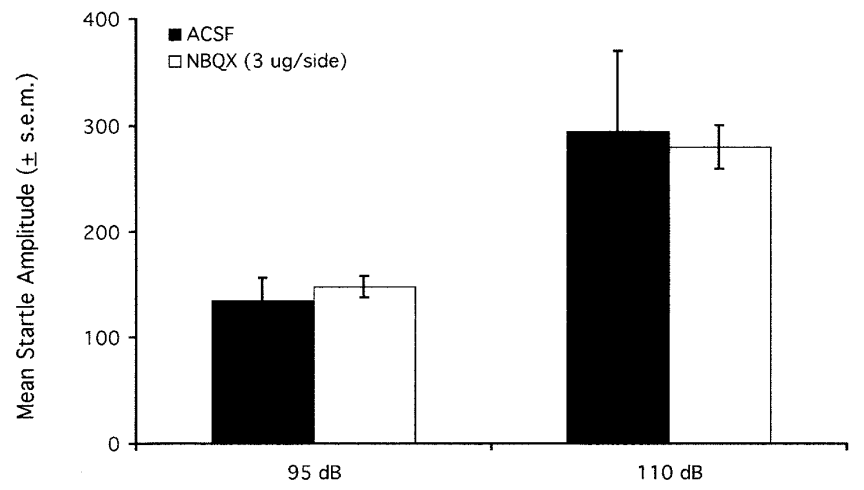

Figure 5. Pre-test infusions of NBQX into the medial nucleus of the amygdala did not influence startle amplitude in untrained rats. 

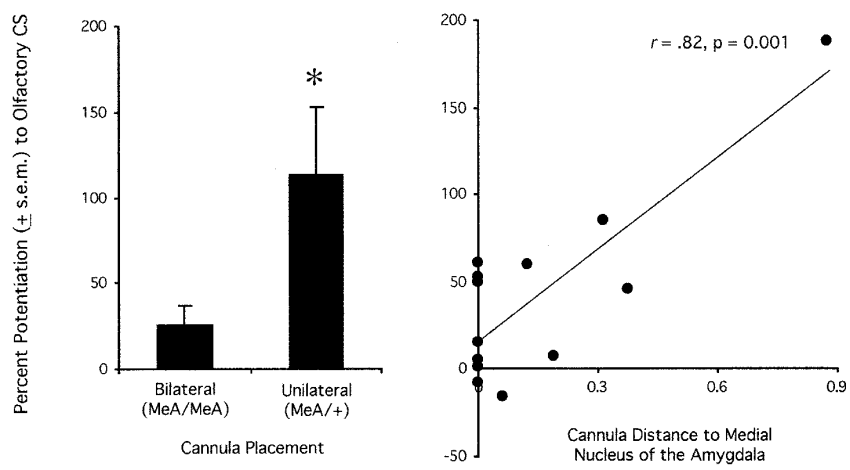

Figure 6. Pre-test NBQX infusions disrupt fear-potentiated startle to an olfactory CS via actions within the medial nucleus of the amygdala. For all NBQX-infused rats from Experiment 4, percent potentiation scores were significantly lower for rats that received bilateral infusions into the medial nucleus of the amygdala (MeA) compared to rats that received one infusion into the medial nucleus and a second infusion elsewhere (left). For these same animals, the distance of the infusion sites from the medial nucleus of the amygdala was significantly correlated with the magnitude of fear-potentiated startle to the olfactory CS (right). ${ }^{*} P<0.05$ vs. ACSF control infusions.

ingfully compare the behavioral effects of bilaterally accurate placements vs. misses). For fear-potentiated startle to context, bilateral infusions of NBQX into the medial nucleus of the amygdala were no more effective than unilateral infusions into the medial nucleus of the amygdala and a second infusion elsewhere $(8 \pm 11[N=22]$ vs. $1 \pm 16[N=7]$ percent potentiation, for bilateral vs. unilateral hits respectively), and there was no correlation between percent potentiation and proximity to any of the four structures examined. It should be noted, however, that the effects on context-potentiated startle were anatomically localized to the ventromedial region of the amygdala insofar as infusions into the basolateral amygdala, as previously noted, did not disrupt the pre- to post-conditioning increases.

\section{Discussion}

The three goals of the present study were (1) to evaluate the generality of a previous finding from Cousens and Otto (1998) indicating that the basolateral amygdala plays a key role in fear expression to olfactory CSs, (2) to determine if the basolateral amygdala also participates in olfactory fear learning, and (3) to evaluate the contribution of the medial nucleus of the amygdala to both. We found (1) that pre-test infusions into the basolateral amygdala of the AMPA/kainate receptor antagonist NBQX, but not the NMDA receptor antagonist AP5, blocked fear-potentiated startle to an olfactory CS, (2) that pre-training AP5 infusions into the basolateral amygdala blocked olfactory fear learning, and (3) that pre-test NBQX infusions into the medial nucleus of the amygdala disrupted fear-potentiated startle to an olfactory CS, as well as fear expression to a visual and contextual CS. We did not, however, find evidence for a role of the medial amygdala nucleus in olfactory fear conditioning.

Our findings with regard to the basolateral amygdala's involvement in fear expression are in agreement with those of Cousens and Otto (1998) who used freezing as a behavioral measure. They are also consistent with those of Cahill and McGaugh (1990) who found that large excitotoxic amygdala lesions disrupted avoidance of a shock-paired odor, and with those of Sananes and Campbell (1989) who reported that lesions of the central nucleus of the amygdala (a major recipient of basolateral projections) abolished heart rate increases also produced by shock-paired odors. These results are consistent, more generally, with results from many other studies that have evaluated the role of the basolateral amygdala in conditioned fear responses to auditory and visual stimuli (cf., Davis 2000; Walker and Davis $2002 b$ ). Thus, despite the notably different organization of olfactory inputs to the amygdala vis-à-vis other modalities, the essential role of the basolateral amygdala in fear expression appears to be preserved.

The finding that pre-training but not pre-test AP5 infusions into the basolateral amygdala disrupted fear-potentiated startle to an olfactory CS is also consistent with previous findings from studies that have used auditory and visual cues as conditioned fear stimuli (cf., Walker and Davis 2002b; but see Fendt 2001). To our knowledge, this is the first study to specifically evaluate the behavioral contribution of the basolateral amygdala to olfactory fear conditioning (i.e., as opposed to fear expression). The results suggest that NMDA receptors within the basolateral amygdala play an important role in triggering the neural changes upon which olfactory fear conditioning depends. That such changes occur within the basolateral amygdala is strongly supported by findings from Rosenkranz and Grace (2002) who found that paired but not unpaired odor-shock presentations led to enhanced odor-evoked post-synaptic potentials recorded intracellularly from basolateral amygdala neurons, and that these increases were largely prevented by intracellular injections during footshock of hyperpolarizing current.

Basolateral amygdala activity soon after training might also be required for the consolidation of olfactory fear memories (Kilpatrick and Cahill 2003). Interestingly, however, for olfactory stimuli that do not require conditioning to evoke fear or anxiety, and for olfactory conditioning to appetitive stimuli, the basolateral amygdala might not be required at all (Cahill and McGaugh 1990; Wallace and Rosen 2001).

The results of Experiments 3 and 4 implicate the medial amygdala nucleus in fear expression to olfactory CSs but do not implicate the medial nucleus in fear conditioning. Because the same CS pathway presumably participates in both, the disruption of performance by pre-test NBQX infusions cannot readily be attributed to a disruption of neural transmission in CS pathways. A more plausible view is that the medial nucleus is either an embedded component of the conditioned response pathway, or an indirect modulator of that pathway. With regard to the former possibility, the medial nucleus projects to the bed nucleus of the stria terminalis (Canteras et al. 1995; Dong et al. 2001) and the bed nucleus of the stria terminalis projects to the central nucleus of the amygdala (e.g., Dong et al. 2000, 2001). Both project to the primary acoustic startle circuit (Rosen et al. 1991; Koch and Ebert 1993; Fendt et al. 1994, 1997; Frankland and Yeomans 1995; Koch and Schnitzler 1997; Shi and Davis 2002) and have been implicated in the potentiation of startle by fear and anxiogenic stimuli (e.g., Koch and Schnitzler 1997; Lee and Davis 1997; Rosen and Davis 1988). As a recipient of projections from the basolateral amygdala (cf., Pitkanen 2000), the medial nucleus is potentially well-positioned to mediate the influence of fear on startle. The medial nucleus might also influence anxiety more generally. Duxon et al. (1997) found that infusions of a $5-\mathrm{HT}_{2 \mathrm{~B}}$ receptor agonist into the medial amygdala nucleus reduced indices of anxiety in the social interaction test although, in the same study, $5-\mathrm{HT}_{2 \mathrm{~B}}$ activation was not anxiolytic in the Vogel punished drinking test.

Analyses of the relation between cannula placement and the effect of these infusions suggested that the disruption of fearpotentiated startle to the olfactory CS was indeed attributable to actions within or very near to the medial amygdala nucleus. First, whereas bilateral placements in the medial nucleus nearly abolished fear-potentiated startle to the olfactory CS, unilateral placements (one cannula in the medial nucleus and a second cannula elsewhere that did not satisfy our inclusion criteria) had no ob-

\section{Learning \& Memory}


vious effect. Thus, the behavioral effects were anatomically specific. Moreover, for odor-potentiated startle, a significant correlation was observed between the behavioral effect and the distance of the cannula from the medial nucleus. Perhaps significantly, this was not the case for fear-potentiated startle to the visual CS, or for the increases in startle amplitude that occurred from the pre-conditioning acclimation session to the postconditioning test session. For these stimuli, infusions elsewhere into the ventromedial amygdala were also effective and there was no such correlation. Thus, the role of the medial nucleus in fearpotentiated startle to nonolfactory CSs remains uncertain.

In light of a previous finding that NBQX infusions directly into the central nucleus of the amygdala disrupt fear-potentiated startle to visual CSs (Walker and Davis 1997), the possibility that the NBQX effects on odor-potentiated startle observed in the present study were due to actions within the central nucleus merits additional consideration. Recent unpublished findings from our laboratory are relevant. Using procedures similar to those used here (see Shi and Davis 1999 for details), C.-J. Shi and M. Davis (unpubl.) found that unilateral NBQX infusions into the medial nucleus of the amygdala did not disrupt fearpotentiated startle to a visual CS (see Fig. 7, left). In contrast, Z. Zhao and M. Davis (unpubl.), using the same behavioral procedures and a similar startle apparatus (see Meloni and Davis 2000 for details), found that unilateral infusions into the central nucleus of the amygdala did abolish fear-potentiated startle to a visual CS (see Fig. 7, right). Hence, if the blockade of fearpotentiated startle to a visual CS by NBQX infused into the medial nucleus was due to diffusion to the central nucleus, one might expect that this blockade would also have occurred with unilateral infusions into the medial nucleus of the amygdala. Because this did not occur, we are doubtful that the effects of NBQX in Experiment $4 \mathrm{~B}$ are attributable to actions within the central nucleus of the amygdala. We have also found that NBQX infusions into the central amygdala nucleus disrupt fear conditioning (pre-training infusions) to a visual CS as well as fearpotentiated startle (pre-test infusions). In the present study, NBQX infusions into the medial nucleus disrupted fearpotentiated startle but did not disrupt fear conditioning. Again, this dissociation is most compatible with the view that our NBQX effects on odor-potentiated startle are not due to diffusion to the medial nucleus.

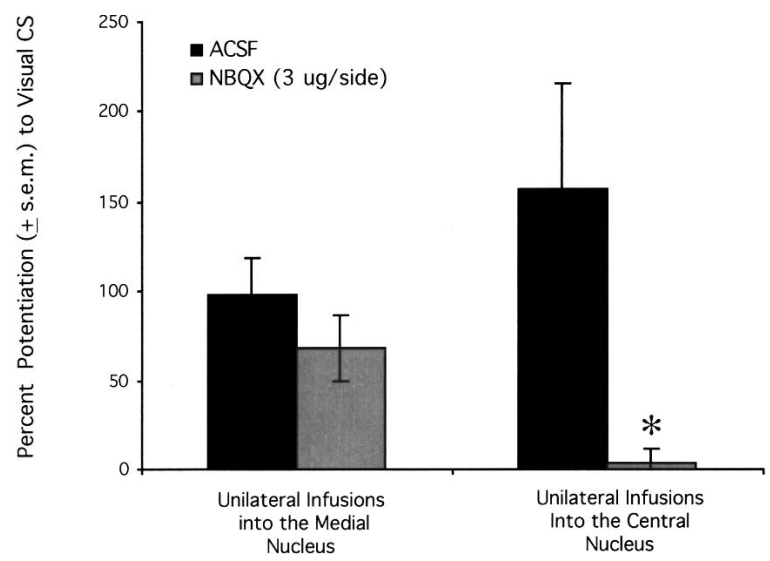

Figure 7. Previously unpublished findings from our laboratory suggest that the effect of pre-test NBQX infusions into the medial nucleus of the amygdala is not due to drug actions within the central nucleus of the amygdala. Whereas unilateral infusions of NBQX into the central nucleus potently disrupt fear-potentiated startle (C.-J. Shi and M. Davis, unpubl.), unilateral infusions into the medial nucleus of the amygdala do not ( $Z$. Zhao and M. Davis, unpubl.). ${ }^{*} P<0.05$ vs. ACSF control infusions.
A comparison with results from lesion studies may also be informative insofar as the behavioral effects of lesions can be attributed with great precision to damage to within a circumscribed area. Pre- as well as post-training excitotoxic lesions of the medial nucleus blocked freezing to a context previously paired with predator odor in Takahashi et al. (2004) but the same group found only a nonsignificant effect of pre-training lesions on freezing to a context that had been paired with footshock ( $\mathrm{Li}$ et al. 2004). Pre-training excitotoxic lesions of the medial amygdala nucleus also blocked freezing to a context previously paired with predator odor in Markham et al. (2004) but, again, did not significantly disrupt freezing to a context previously paired with footshock. Pre-training electrolytic lesions incompletely disrupted freezing to a footshock-paired context in Holahan and White (2002), and pre-training excitotoxic lesions had no effect on conditioned freezing to an auditory CS in Nader et al. (2001). Although the designs of these studies are not strictly comparable to our own, the general pattern of results appears to be similar. Whether an odor is used as a CS, as in our study, or as a unconditioned stimuli (US), as in Takahashi et al. (2004) and Markham et al. (2004), there is considerable consistency regarding the importance of the medial amygdala nucleus in fear-conditioning paradigms that use odor. For fear-conditioning paradigms that use nonolfactory stimuli, the results appear to be less consistent.

As indicated elsewhere, we also observed that baseline startle amplitude increased markedly from the pre-conditioning acclimation session to the post-conditioning test session and that these increases were context-dependent (see also McNish et al. 1997). Context-potentiated startle was not observed in rats that received pre-test NBQX infusions into the medial amygdala nucleus. Most surprisingly, however, context conditioning and context-potentiated startle appeared to be completely intact in rats that received pre-test NBQX or pre-training AP5 infusions into the basolateral amygdala. The disruption of odorpotentiated startle in the same animals and in the same test session following basolateral amygdala infusions provides an important positive control and limits the range of possible interpretations (i.e., insufficient dose or inaccurate placement) for the failure to also disrupt context-potentiated startle. Although many studies have shown that contextual fear conditioning and conditioned fear to contextual cues can be disrupted by treatments that interfere with basolateral amygdala function (e.g., Fanselow and Kim 1994; Helmstetter and Bellgowan 1994; Muller et al. 1997; Goosens and Maren 2001, 2003; Rodrigues et al. 2001; Wallace and Rosen 2001) our results are not wholly without precedent.

Maren (1999) found that although basolateral amygdala lesions slowed the emergence of freezing to a context CS, asymptotic levels after additional training were comparable to those observed in sham-lesioned controls. In the same animals, basolateral amygdala lesions completely blocked freezing to an auditory CS and this deficit was not overcome by additional training (see also Cahill et al. 2000; Berlau and McGaugh 2003). Selden et al. (1991) found that pre-training basolateral amygdala lesions disrupted lick suppression produced by an auditory CS, but did not disrupt avoidance by the same animals of the compartment in which they had previously received shocked. In our own laboratory, we recently noted that rats that received AP5 infusions into the basolateral amygdala prior to 30 light-shock pairings showed no evidence of fear conditioning to the visual cue (i.e., on CS-noise trials) and initially showed no evidence of fear conditioning to the context (i.e., on noise-alone trials). During testing however, startle amplitude on both trial types increased abruptly and to a comparable level once the first light stimulus was presented (see Walker and Davis 2002b). We believe that the visual stimulus in that study may have acted as a salient element 
of the context rather than as a CS, triggering latent contextual fear that had been disrupted but not blocked by pre-training AP5 infusions. Even in those studies in which amygdala manipulations have been shown to impair context conditioning or fear expression, when context and discrete cue-elicited fear have been measured in the same study, the effects on the former are often weaker than on the latter (e.g. Helmstetter and Bellgowan 1994; Rodrigues et al. 2001).

We are uncertain what contributes to the variable effects of amygdala manipulations on context conditioning and fear expression. One possibility, for example, is that context trained as a foreground stimulus (i.e., paired with shock in the absence of an explicit discrete CS) may be more or less susceptible to amygdala manipulations than context trained as a background stimulus. However, amygdala manipulations have been found to disrupt fear behaviors elicited by contexts trained as foreground (Fanselow and Kim 1994) as well as background (e.g., Muller et al. 1997) stimuli and, in other studies, have been found not to disrupt fear behaviors elicited by contexts trained as foreground (Maren 1999) or as background (present results) stimuli.

With specific reference to our findings, it is also possible that receptors within the amygdala other than those targeted mediate contextual processes. Perhaps, for example, shortduration responses to short-duration CSs are mediated by ionotropic glutamatergic receptors within the basolateral amygdala, whereas longer duration responses to longer duration CSs (e.g., context) are mediated by peptide or metabotropic receptors.

A differential involvement of the amygdala in context versus discrete cue conditioning may be relevant to the longstanding debate as to whether the amygdala is a critical site of neural plasticity in aversive learning paradigms (e.g., Fanselow and LeDoux 1999) or, instead, a brain area that modulates memory storage elsewhere (e.g., Cahill et al. 1999). Evidence for the latter view comes largely from studies that have found incomplete effects of amygdala manipulations on tasks that have assessed retention using avoidance of shock-associated contexts as the primary behavioral measure (e.g. Berlau and McGaugh 2003; Vazdarjanova and McGaugh 1998). From the standpoint of the present discussion, it would be interesting to compare directly the influence of amygdala manipulations on avoidance of shock-paired contexts with avoidance elicited by discrete unimodal CSs.

In summary, our results indicate that the basolateral subdivision of the amygdala plays an important role in fearpotentiated startle and in fear conditioning to olfactory cues. The results also implicate the medial nucleus of the amygdala in fear expression, at least to olfactory cues. We also found that context conditioning and fear-potentiated startle to a shock-associated context was not disrupted by basolateral amygdala manipulations that did disrupt fear conditioning and expression to an olfactory CS.

\section{Materials and Methods}

\section{Animals}

Male Sprague-Dawley rats (Charles River) were maintained on a 12-h light/12-h dark cycle (lights on at $0800 \mathrm{~h}$ ) with food and water available ad libitum. Rats were initially group-housed in 45 $\times 20 \times 24-\mathrm{cm}$ (depth $\times$ width $\times$ height) polycarbonate cages (four rats per cage) and individually housed, following surgery, in $20 \times 19 \times 24-\mathrm{cm}$ hanging wire-mesh cages. At surgery, rat weights ranged from 275 to $350 \mathrm{~g}$.

\section{Apparatus}

Rats were trained and tested in two identical $9 \times 14 \times 10$-cm (depth $\times$ width $\times$ height; internal dimensions) Plexiglas and wire-mesh cages, each suspended between compression springs within a steel frame and located, together, within a customdesigned $60 \times 79.5 \times 59.5-\mathrm{cm}$ sound-attenuating chamber lined with $6.3 \mathrm{~mm}$ thick Plexiglas. The floor of each cage consisted of four $6.0-\mathrm{mm}$ diameter stainless steel bars spaced $18 \mathrm{~mm}$ apart.

Affixed to the bottom of each cage was an Endevco accelerometer (Model 2217E). Cage movement (e.g., produced by the rat's startle response) resulted in displacement of the accelerometer that, in turn, produced a voltage output proportional to the velocity of cage movement. The accelerometer's output was amplified by an Endevco Model 104 amplifier and digitized on a scale of 0-2500 units by an InstruNET device (GW Instruments, Model 100B) interfaced to a Macintosh G3 computer. Startle amplitude was defined as the maximal peak-to-peak voltage that occurred during the first $300 \mathrm{msec}$ after onset of the startleeliciting noise burst.

Startle responses were evoked by $50-\mathrm{msec} 95-\mathrm{dB}$ white-noise bursts (5-msec rise-decay time, $0-22 \mathrm{kHz}$ ) generated by a Macintosh G3 computer soundfile, amplified by a Radio Shack amplifier (Model MPA-200), and delivered through high frequency speakers (Radio Shack Supertweeter) located $8 \mathrm{~cm}$ in front of each cage. Background noise (60-dB wideband) was produced by an ACO Pacific white-noise generator (Model 3024) and was delivered through the same speakers as those used to provide whitenoise bursts. Sound level measurements were made with a Brüel \& Kjaer model 2235 sound-level meter (A scale; random input) with the microphone (Type 4176) located $10 \mathrm{~cm}$ from the center of the speaker, which approximates the distance of the rat's ear from the speaker during testing.

The olfactory CS and the means for delivering it have been described in detail elsewhere (Paschall and Davis 2002). In brief, a continuous flow of air was delivered from a compressed-air cylinder at a rate of $1.0 \mathrm{~L} / \mathrm{min}$ through a small port $(1.3-\mathrm{mm}$ lumen diameter) positioned just above a $12.5 \mathrm{~mm}$ diameter opening in the top of each cage. For delivery of the olfactory stimulus, a computer-controlled solenoid (Model H15-03, Coulbourn Instruments) was opened for $4 \mathrm{sec}$, thereby diverting clean air from the compressed-air cylinder into and through a sealed $135-\mathrm{cm}^{3}$ glass jar that contained $20 \mathrm{ml}$ of $5 \%$ (vol/vol) amyl acetate (i.e., the odorant) in propylene glycol solution. The inlet and outlet ports of the glass jar were positioned above the solution such that clean air from the tank mixed with the amyl acetate-containing vapor. The output was then mixed in a 3:5 ratio with clean air before flowing into the cage. To deflect air that would otherwise flow directly onto the rat's back, a $2.5 \times 2.5-\mathrm{cm}$ sheet-metal plate was positioned just inside the test cage, slightly below the port through which air was delivered.

The chamber $\left(0.284 \mathrm{~m}^{3}\right.$ total volume $)$ was actively exhausted into the building's ventilation system at a rate of 0.0114 $\mathrm{m}^{3} / \mathrm{sec}$. Thus, a volume of air equal to the chamber's total volume was vented every 25 sec. Previous results with fearconditioned rats indicate that with these procedures startle amplitude returns to baseline levels within 30 sec of solenoid closure (Paschall and Davis 2002). Cages were cleaned daily with warm tap water and 95\% alcohol, and were air dried overnight.

A 4-sec visual CS (140 lux) was used for Experiment 4B. This CS was produced by an 8 -W fluorescent bulb (100- $\mu$ sec rise time) located $10 \mathrm{~cm}$ behind each cage. Luminosity was measured using a VWR light meter.

A context switch experiment was also performed. For this experiment, rats were trained in a $24 \times 31 \times 26 \mathrm{~cm}$ with 16 $0.5-\mathrm{cm}$ diameter floor bars (spaced $18 \mathrm{~mm}$ apart) with $24-\mathrm{cm}$ metal-link chains hanging freely from a position $11.0 \mathrm{~cm}$ diagonal to each corner. During training, background noise was off and a 150 lux houselight was on. The olfactory stimulus was delivered through Pharmed Tygon tubing (3.2 $\mathrm{mm}$ inner diameter) that was routed through the ceiling of the training chamber. The end of the tubing hung approximately $7 \mathrm{~cm}$ above the floorbars.

The unconditioned stimulus for all experiments was a 0.5sec 0.4-mA scrambled floorbar shock. Shock intensity was measured with a $1-\mathrm{kW}$ resistor across a differential channel of an oscilloscope in series with a 100-kW resistor connected between

\section{Learning \& Memory}

www.learnmem.org 
adjacent floor bars within each cage. Current was defined as the root-mean-square voltage across the $1-\mathrm{kW}$ resistor where $\mathrm{mA}=$ $0.707 \times 0.5 \times$ peak-to-peak voltage. Shocks were produced by LeHigh Valley shock generators (SGS-004).

The presentation and sequencing of all stimuli was under the control of the Macintosh G3 computer using customdesigned software (The Experimenter; Glassbeads Inc.).

\section{Surgery}

Rats were anesthetized with Nembutal (sodium pentobarbital; 50 $\mathrm{mg} / \mathrm{kg}$ ip) and placed in an ASI, Inc. stereotaxic frame with the nosebar set to $-3.8 \mathrm{~mm}$ (flat-skull position). The skull was exposed and 22-gauge guide cannulae (Plastic Products, Model C313G) were lowered bilaterally into the basolateral amygdala $(\mathrm{AP}=-3.3, \mathrm{DV}=-8.2, \mathrm{ML}= \pm 5.4 \mathrm{~mm}$ from bregma $)$ or the medial nucleus of the amygdala $(\mathrm{AP}=-3.0, \mathrm{DV}=-9.5, \mathrm{ML}= \pm 3.6$ $\mathrm{mm}$ from bregma). Dummy cannulae (Plastic Products, Model C313DC/l) were inserted into each guide cannula to prevent clogging. The tip of each extended approximately $1 \mathrm{~mm}$ past the end of the guide cannula. Jeweler screws were anchored to the skull and the entire assembly was cemented in place using Cranioplastic Powder (Plastic Products). A minimum of $8 \mathrm{~d}$ elapsed between surgery and the behavioral procedures.

\section{Drugs and infusion procedure}

Rats were infused with the NMDA receptor antagonist D,L-AP5 (Sigma-Aldrich), the AMPA/kainate receptor antagonist NBQX (Tocris Cookson Inc.) disodium salt, or artificial cerebrospinal fluid (ACSF). Infusions $(0.25 \mu \mathrm{L} / \mathrm{min}, 0.5 \mu \mathrm{L}$ total volume) were made through 28-gauge injection cannulae (Plastic Products, Model C313I) that were attached by polyethylene tubing to a Hamilton microsyringe. Injection cannulae were left in place for 2 min after the infusion was completed.

Pre-test infusions were completed immediately before the animals were placed into the test cages. The CS-noise and noisealone test trials, from which fear-potentiated scores were derived, began 20 min later. For pre-training administration, infusions were completed $15 \mathrm{~min}$ before animals were placed into the cages, and CS-shock pairings began 5 min later. Thus, both testing and training began approximately $20 \mathrm{~min}$ after the infusion.

\section{Behavioral procedures}

\section{Acclimation session}

On each of two consecutive days, rats were placed into the test cages and after $5 \mathrm{~min}$, presented with 30 95-dB startle-eliciting noise bursts (onset-to-onset interstimulus interval [ISI] $=30 \mathrm{sec}$ ). On the basis of these results, rats were sorted into different treatment groups such that each treatment group began with equivalent mean baseline startle levels.

\section{Fear conditioning}

Within three days of the final acclimation session, rats were returned to the same chamber whereupon they received either five odor-shock (Experiments 1, 2, 3, and 4A) or five light-shock (Experiment $4 \mathrm{~B}$ ) pairings. The first pairing occurred $5 \mathrm{~min}$ after placement into the startle chamber and successive shocks occurred every $4 \mathrm{~min}$. For each pairing, the 0.5 -sec shock was delivered $3.5 \mathrm{sec}$ after onset of the 4.0 -sec CS.

\section{Fear-potentiated startle test}

Approximately $48 \mathrm{~h}$ later, rats were again returned to the same chamber in which they had previously received shocks. Five minutes later, the first of 30 95-dB startle-eliciting noise bursts was presented. Successive stimuli occurred every $30 \mathrm{sec}$. Rats then received 40 test trials consisting of 10 repetitions of a single CS test trial followed by three noise-alone test trials. For CS test trials, the $95-\mathrm{dB}$ noise burst was presented $3.5 \mathrm{sec}$ after onset of either the odor (Experiments 1, 2,3, and 4A) or light (Experiment 4B) CS. For noise-alone test trials, the 95-dB noise burst was presented alone. The ISI for all stimuli was $30 \mathrm{sec}$.

\section{Statistical analyses}

For each rat, the mean startle amplitude on noise-alone and on CS test trials was determined, and a percent change score was calculated (mean startle amplitude on CS-noise test trials divided by the mean startle amplitude on noise-alone test trials $\times 100$ minus 100). Percent change scores were used (i.e., vs. absolute difference scores) because we previously found that they remain stable across large variations in baseline startle amplitude (up to 10 -fold in Walker and Davis 2002a). These scores were then analyzed using ANOVA and/or two-tailed $t$-tests as indicated in the Results section.

Changes in baseline startle from the pre-conditioning acclimation session to the post-conditioning test session, shown elsewhere to reflect context conditioning, were similarly calculated (i.e., mean startle amplitude of the 30 noise-alone trials which occurred at the beginning of the test session divided by the mean startle amplitude of the 30 noise-alone trials of the second acclimation session $\times 100$ minus 100 ).

For all comparisons, the criterion for significance was $P<0.05$.

\section{Histology}

Rats were sacrificed by chloral hydrate overdose and perfused intracardially with $0.9 \%$ saline (wt/vol) followed by $10 \%$ formalin (vol/vol). The brains were removed and immersed in a $30 \%$ sucrose-formalin solution (wt/vol) for at least three days, after which $40-\mu \mathrm{m}$ coronal sections were cut through the area of interest. Every fourth section was mounted and stained with cresyl violet.

Cannula placements, and the determination as to whether the cannula was within or sufficiently near the intended target to be scored as a hit, were judged by a scorer blind to the animal's group assignment and behavioral data. To be scored as an accurate placement, cannula tips were required to be within or no further than $0.5 \mathrm{~mm}$ from the intended target (i.e., either the basolateral amygdala complex [e.g., the lateral, basolateral, and basomedial nuclei] for Experiments 1 and 2, or the medial amygdala nucleus for Experiments 3 and 4). Because white matter tracts have previously been shown to be barrier's to diffusion (e.g., Morris et al. 1989), data from animals with cannula tips located on the opposite side of a white matter tract (i.e., cannula intended for the medial amygdala that were medial to the optic tract, or cannula intended for the basolateral amygdala that were lateral to the external capsule) were always excluded unless the guide cannula sheared through the tract thereby allowing for diffusion to the intended target.

With the dose and infusion parameters used in the present study and similar inclusion criteria, we previously reported that NBQX infusions into the basolateral but not the central amygdala disrupt the facilitatory effects of sustained bright light on startle (Walker and Davis 1997). We have also observed that NBQX infusions into the ventral cochlear nucleus disrupt toneevoked compound action potentials only when the cannula tips are within $1.0 \mathrm{~mm}$ of the ventral cochlear nucleus (E.G. Meloni and M. Davis, unpubl.). Similarly, with the same dose of AP5 as that used here, albeit with a nominally smaller infusion volume $(0.3 \mu \mathrm{L}$ vs. $0.5 \mu \mathrm{L})$, Fanselow and Kim (1994) reported that D,LAP5 disrupted fear conditioning when infused into the basolateral amygdala but not when infused into the central amygdala nucleus. Thus, we believe that these procedures and inclusion criteria are appropriate for evaluating the contribution of the basolateral and medial amygdala to fear acquisition and potentiated startle.

\section{Acknowledgments}

This research was supported by National Institute of Mental Health Grants MH 47840, MH 58922, MH 52384, MH 59906, the Woodruff Foundation, and the Science and Technology Center (The Center for Behavioral Neuroscience of the National Science Foundation under Agreement No. IBN-9876754). 


\section{References}

Alheid, G., deOlmos, J.S., and Beltramino, C.A. 1995. Amygdala and extended amygdala. In The rat nervous system (ed. G. Paxinos), pp. 495-578. Academic Press, New York.

Berlau, D.J. and McGaugh, J.L. 2003. Basolateral amygdala lesions do not prevent memory of context-footshock training. Learn. Mem. 10: $495-502$

Cahill, L. and McGaugh, J.L. 1990. Amygdaloid complex lesions differentially affect retention of tasks using appetitive and aversive reinforcement. Behav. Neurosci. 104: 532-543.

Cahill, L., Weinberger, N., Roozendaal, B., and McGaugh, J. 1999. Is the amygdala a locus of "conditioned fear"? Some questions and caveats. Neuron 23: 227-228.

Cahill, L., Vazdarjanova, A., and Setlow, B. 2000. The basolateral amygdala complex is involved with, but is not necessary for, rapid acquisition of Pavlovian "fear conditioning." Eur. J. Neurosci. 12: 3044-3050.

Campeau, S., Miserendino, M.J.D., and Davis, M. 1992. Intra-amygdala infusion of the N-methyl-D-Aspartate receptor antagonist AP5 blocks acquisition but not expression of fear-potentiated startle to an auditory conditioned stimulus. Behav. Neurosci. 106: 569-574.

Canteras, N.S., Simerly, R.B., and Swanson, L.W. 1995. Organization of projections from the medial nucleus of the amygdala: A PHAL study in the rat. J. Comp. Neurol. 360: 213-245. [erratum appears in J. Comp. Neurol. 1996. 369: 328-330].

Cousens, G. and Otto, T. 1998. Both pre- and post-training excitotoxic lesions of the basolateral amygdala abolish the expression of olfactory and contextual fear conditioning. Behav. Neurosci. 112: 1092-1103.

Davis, M. 2000. The role of the amygdala in conditioned and unconditioned fear and anxiety. In The Amygdala (ed. J.P. Aggleton), vol. 2, pp. 213-287. Oxford University Press, Oxford, UK.

DeOlmos, J., Alheid, G.F., and Beltramino, C.A. 1985. Amygdala. In The Rat Nervous System (ed. G. Paxinos), pp. 223-334. Academic Press, Orlando, FL.

Dong, H.W., Petrovich, G.D., and Swanson, L.W. 2000. Organization of projections from the juxtacapsular nucleus of the BST: A PHAL study in the rat. Brain Res. 859: $1-14$.

. 2001. Topography of projections from amygdala to bed nuclei of the stria terminalis. Brain Res. Brain Res. Rev. 38: 192-246.

Duxon, M.S., Kennett, G.A., Lightowler, S., Blackburn, T.P., and Fone, K.C. 1997. Activation of 5-HT2B receptors in the medial amygdala causes anxiolysis in the social interaction test in the rat. Neuropharmacology 36: 601-608.

Fanselow, M.S. and Kim, J.J. 1994. Acquisition of contextual Pavlovian fear conditioning is blocked by application of an NMDA receptor antagonist D,L-2-amino-5-phosphonovaleric acid to the basolateral amygdala. Behav. Neurosci. 108: 210-212.

Fanselow, M. and LeDoux, J. 1999. Why we think plasticity underlying Pavlovian fear conditioning occurs in the basolateral amygdala. Neuron 23: 229-232.

Fendt, M. 2001. Injections of the NMDA receptor antagonist aminophosphonopentanoic acid into the lateral nucleus of the amygdala block the expression of fear-potentiated startle and freezing. J. Neurosci. 21: 4111-4115.

Fendt, M. and Fanselow, M.S. 1999. The neuroanatomical and neurochemical basis of conditioned fear. Neurosci. Biobehav. Rev. 23: 743-760.

Fendt, M., Koch, M., and Schnitzler, H.-U. 1994. Lesions of the central grey block the sensitization of the acoustic startle response in rats. Brain Res. 661: 163-173.

. 1997. Corticotropin-releasing factor in the caudal pontine reticular nucleus mediates the expression of fear-potentiated startle in the rat. Eur. J. Neurosci. 9: 299-305.

Frankland, P.W. and Yeomans, J.S. 1995. Fear-potentiated startle and electrically evoked startle mediated by synapses in rostrolateral midbrain. Behav. Neurosci. 109: 669-680.

Gewirtz, J. and Davis, M. 1997. Second order fear conditioning prevented by blocking NMDA receptors in the amygdala. Nature 388: $471-474$.

Goosens, K.A. and Maren, S. 2001. Contextual and auditory fear conditioning are mediated by the lateral, basal, and central amygdaloid nuclei in rats. Learn. Mem. 8: 148-155.

. 2003. Pre-training NMDA receptor blockade in the basolateral complex, but not the central nucleus, of the amygdala prevents savings of conditional fear. Behav. Neurosci. 117: 738-750.

Groenink, L., Joordens, R.J., Hijzen, T.H., Dirks, A., and Olivier, B. 2000. Infusion of flesinoxan into the amygdala blocks the fear-potentiated startle. Neuroreport 11: 2285-2288.

Helmstetter, F.J. and Bellgowan, P.S. 1994. Effects of muscimol applied to the basolateral amygdala on acquisition and expression of contextual fear conditioning in rats. Behav. Neurosci. 108: $1005-1009$.

Herzog, C. and Otto, T. 1997. Odor-guided fear conditioning in rats: 2 . Lesions of the anterior perirhinal cortex disrupt fear conditioned to the explicit conditioned stimulus but not to the training context. Behav. Neurosci. 111: 1265-1272.

Holahan, M.R. and White, N.M. 2002. Conditioned memory modulation, freezing, and avoidance as measures of amygdala-mediated conditioned fear. Neurobiol. Learn. Mem. 77: 250-275.

Kilpatrick, L. and Cahill, L. 2003. Modulation of memory consolidation for olfactory learning by reversible inactivation of the basolateral amygdala. Behav. Neurosci. 117: 184-188.

Koch, M. and Ebert, U. 1993. Enhancement of the acoustic startle response by stimulation of an excitatory pathway from the central amygdala/basal nucleus of Meynert to the pontine reticular formation. Exp. Brain Res. 93: 231-241.

Koch, M. and Schnitzler, H.-U. 1997. The acoustic startle response in rats-circuits mediating evocation, inhibition and potentiation. Behav. Brain Res. 89: 35-49.

LeDoux, J.E. 2000. The amygdala and emotion: A view through fear. In The Amygdala (ed. J.P. Aggleton), pp. 289-310. Oxford University Press, New York.

LeDoux, J.E., Cicchetti, P., Xagoraris, A., and Romanski, L.M. 1990. The lateral amygdaloid nucleus: Sensory interface of the amygdala in fear conditioning. J. Neurosci. 10: 1062-1069.

Lee, Y. and Davis, M. 1997. Role of the hippocampus, bed nucleus of the stria terminalis and amygdala in the excitatory effect of corticotropin releasing hormone on the acoustic startle reflex. $J$. Neurosci. 17: 6434-6446.

Lee, H.J., Choi, J.S., Brown, T.H., and Kim, J.J. 2001. Amygdalar NMDA receptors are critical for the expression of multiple conditioned fear responses. J. Neurosci. 21: 4116-4124.

Li, C.-I.L., Maglinao, T.L., and Takahashi, L.K. 2004. Medial amygdala modulation of predator odor-induced unconditioned fear in the rat. Behav. Neurosci. 118: 324-332.

Maren, S. 1999. Neurotoxic basolateral amygdala lesion impair learning and memory but not performance of conditional fear in rats. $J$. Neurosci. 19: 8696-8703.

Markham, C.M., Park, Y., Blanchard, R.J., and Blanchard, D.C. 2004. Effects of ibotenic acid lesions of the medial amygdala on unconditioned and conditioned responses to predatory stimuli. Abstract Viewer Itinerary Planner. Program No. 784.786. Society for Neuroscience, Washington, D.C.

McDonald, A.J. 1998. Cortical pathways to the mammalian amygdala. Prog. Neurobiol. 55: 257-332.

McNish, K.A., Gewirtz, J.C., and Davis, M. 1997. Evidence of contextual fear conditioning following lesions of the hippocampus: A disruption of freezing but not fear-potentiated startle. J. Neurosci. 17: 9353-9360.

Meloni, E.G. and Davis, M. 2000. GABA in the deep layers of the superior colliculus mediates the enhancement of startle by the dopamine D1 receptor agonist SKF 82958. J. Neurosci. 20: $5374-5381$.

Miserendino, M.J.D., Sananes, C.B., Melia, K.R., and Davis, M. 1990. Blocking of acquisition but not expression of conditioned fear-potentiated startle by NMDA antagonists in the amygdala. Nature 345: 716-718.

Morris, R.G.M., Halliwell, R., and Bowery, N. 1989. Synaptic plasticity and learning: II. Do different kinds of plasticity underlie different kinds of learning. Neuropsychologia 27: 41-59.

Muller, J., Corodimas, K.P., Fridel, Z., and LeDoux, J.E. 1997. Functional inactivation of the lateral and basal nuclei of the amygdala by muscimol infusion prevents fear conditioning to an explicit conditioned stimulus and to contextual stimuli. Behav. Neurosci. 111: 683-691.

Nader, K., Majidishad, P., Amorapanth, P., and LeDoux, J.E. 2001. Damage to the lateral and central, but not other, amygdaloid nuclei prevents the acquisition of auditory fear conditioning. Learn. Mem. 8: $156-163$.

Paschall, G.Y. and Davis, M. 2002. Olfactory mediated fear potentiated startle. Behav. Neurosci. 116: 4-12.

Paxinos, G. and Watson, C. 1997. The rat brain in stereotaxic coordinates. Academic Press, San Diego, CA.

Pitkanen, A. 2000. Connectivity of the rat amygdala complex. In Amygdala (ed. J.P. Aggleton), pp. 31-116. Oxford University Press, New York.

Pitkanen, A., Savander, V., and LeDoux, J.E. 1997. Organization of intra-amygdaloid circuitries in the rat: An emerging framework for understanding functions of the amygdala. Trends Neurosci. 20: $517-523$.

Rodrigues, S.M., Schafe, G.E., and LeDoux, J.E. 2001. Intra-amygdala

\section{Learning \& Memory}


blockade of the NR2B subunit of the NMDA receptor disrupts the acquisition but not the expression of fear conditioning. J. Neurosci. 21: 6889-6896.

Rosen, J.B. and Davis, M. 1988. Enhancement of acoustic startle by electrical stimulation of the amygdala. Behav. Neurosci. 102: $195-202$

Rosen, J.B., Hitchcock, J.M., Sananes, C.B., Miserendino, M.J.D., and Davis, M. 1991. A direct projection from the central nucleus of the amygdala to the acoustic startle pathway: Anterograde and retrograde tracing studies. Behav. Neurosci. 105: 817-825.

Rosenkranz, J.A. and Grace, A.A. 2002. Dopamine-mediated modulation of odour-evoked amygdala potentials during pavlovian conditioning. Nature 417: 282-287.

Sananes, C.B. and Campbell, B.A. 1989. Role of the central nucleus of the amygdala in olfactory heart rate conditioning. Behav. Neurosci. 103: $519-525$.

Schettino, L.F. and Otto, T. 2001. Patterns of Fos expression in the amygdala and ventral perirhinal cortex induced by training in an olfactory fear conditioning paradigm. Behav. Neurosci. 115: $1257-1272$.

Selden, N.R., Everitt, B.J., Jarrard, L.E., and Robbins, T.W. 1991. Complementary roles for the amygdala and hippocampus in aversive conditioning to explicit and contextual cues. Neurosci. 42: 335-350.

Shi, C.-J. and Davis, M. 1999. Pain pathways involved in fear conditioning measured with fear-potentiated startle: Lesion studies. J. Neurosci. 19: 420-430.

. 2002. A GABAergic projection from the central extended amygdala to the deep mesencephalic nucleus in rats. Abstract Viewer
Itinerary Planner, Program No. 284.214. Society for Neuroscience, Washington, D.C.

Takahashi, L.K., Dar, Y., Hubbard, D.T., and Lee, I. 2004. Unconditioned and conditioned fear induced by predator odor involve the medial and basolateral amygdala. Abstract Viewer Itinerary Planner, Program No. 783.714. Society for Neuroscience, Washington, D.C.

Vazdarjanova, A. and McGaugh, J.L. 1998. Basolateral amygdala is not critical for cognitive memory of contextual fear conditioning. Proc. Natl. Acad. Sci. 95: 15003-15007.

Walker, D.L. and Davis, M. 1997. Double dissociation between the involvement of the bed nucleus of the stria terminalis and the central nucleus of the amygdala in light-enhanced versus fear-potentiated startle. J. Neurosci. 17: 9375-9383.

. 2002a. Quantifying fear potentiated startle using absolute versus percent increase scoring methods: Implications for the neurocircuitry of fear and anxiety. Psychopharmacology 164: 318-328. . 2002b. The role of glutamate receptors within the amygdala in fear learning, fear-potentiated startle, and extinction. Pharmacol. Biochem. Behav. 71: 379-392.

Wallace, K.J. and Rosen, J.B. 2001. Neurotoxic lesions of the lateral nucleus of the amygdala decrease conditioned fear but not unconditioned fear of a predator odor: Comparison with electrolytic lesions. J. Neurosci. 21: 3619-3627.

Received October 1, 2004; accepted in revised form January 4, 2005. 


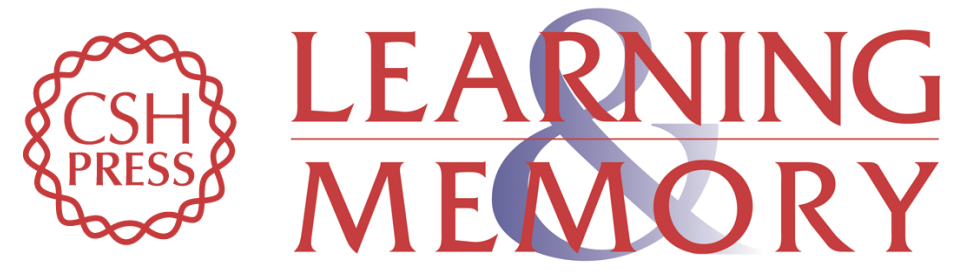

\section{Glutamate receptor antagonist infusions into the basolateral and medial amygdala reveal differential contributions to olfactory vs. context fear conditioning and expression}

David L. Walker, Gayla Y. Paschall and Michael Davis

Learn. Mem. 2005, 12:

Access the most recent version at doi:10.1101//m.87105

References This article cites 54 articles, 15 of which can be accessed free at: http://learnmem.cshlp.org/content/12/2/120.full.html\#ref-list-1

License

Email Alerting

Receive free email alerts when new articles cite this article - sign up in the box at the Service top right corner of the article or click here. 